(C) [2008] IEEE. Reprinted, with permission, from [Jin Yang, David G. Dorrell and John E. Fletcher, EFault ridethrough of doubly-fed induction generator with converter protection schemes, Sustainable Energy Technologies, 2008. ICSET 2008. IEEE International Conference on 24-27 Nov. 2008]. This material is posted here with permission of the IEEE. Such ermission of the IEEE does not in any way imply IEEE endorsement of any of the University of Technology, Sydney's products or services. Internal or personal use of this material is permitted. However, permission to reprint/republish this material for advertising or promotional purposes or for creating new collective works for resale or redistribution must be obtained from the IEEE by writing to pubs-permissions@ieee.org. By choosing to view this document, you agree to all provisions of the copyright laws protecting it 


\title{
Fault Ride-Through of Doubly-Fed Induction Generator with Converter Protection Schemes
}

\author{
Jin Yang, David G. Dorrell, Senior Member, IEEE, and John E. Fletcher, Senior Member, IEEE
}

\begin{abstract}
This paper from the point view of wind farm fault ride-through (FRT) capability, discusses the performance of converter protection schemes to it. Different resistor protection methods are summarized and then a new combined protection with crowbar (CB) and series dynamic resistor (SDR) is proposed. With the analysis of rotor current during fault, resistance values are calculated for practical application. The rotor high current reduction performance is simulated with MATLAB/Simulink. Fault ride-through performance including the reactive power supply, torque fluctuation and rotor speed with crowbar and series dynamic resistor are compared. The proposed method is an alternative for further protection and requirements of wind farm riding-through grid disturbances.

Index Terms-Fault ride-through (FRT), Doubly-fed induction generator (DFIG), converter protection, wind generation.
\end{abstract}

\section{NOMENCLATURE}

$\vec{v}, \vec{i}, \vec{\psi} \quad$ Voltage, current and flux vector.

$R_{s}, R_{r}, L_{s}, L_{r} \quad$ Stator, rotor resistances and self-inductances. $L_{m} \quad$ Magnetizing inductance.

$\omega_{s}, \omega, \omega_{r} \quad$ Synchronous, rotor and slip angular frequency.

$P_{s}, Q_{s} \quad$ Stator side active and reactive power.

$s, r \quad$ Stator and rotor subscripts.

$n \quad$ Nominal value subscripts.

\section{INTRODUCTION}

$\mathrm{F}$ AULT Ride-Through (FRT) capability is one of the basic requirements for wind farms. There are two aspects to fault ride-through: to continue power supply without breaking any part of the system and to resume normal operation after clearance of the fault. The doubly-fed induction generator (DFIG) is presently the most popular wind turbine system for large-scale generation. However, a significant disadvantage of the DFIG is its vulnerability to grid disturbances and fluctuations because the stator windings are connected directly to the grid through a transformer and switchgear; the rotor-side is buffered from the grid via a partially-rated converter.

To protect the wind farm from interruptions due to onshore grid faults and wind farm faults, crowbar protection has emerged as a protection method. A crowbar is a resistor that is connected in parallel with the rotor winding on occurrence of an interruption, bypassing the rotor-side converter (RSC). They were originally used with small wind farms. No fault ride-through requirement was required and the wind turbine

J. Yang is with the Department of Electronics and Electrical Engineering, University of Glasgow, G12 8LT, UK (e-mail: j.yang@elec.gla.ac.uk).

D. G. Dorrell is with the Mechatronics and Intelligent Systems Group, Engineering, University of Technology, Sydney, NSW, Australia (e-mail: david.dorrell@uts.edu.au).

J. E. Fletcher is with the Department of Electronic and Electrical Engineering, University of Strathclyde, G1 1XW, UK (e-mail: john.fletcher@eee.strath.ac.uk). system was disconnected directly. This is called passive crowbar protection, which does not need complex control.

As fault ride-through requirements have developed, an active crowbar control scheme has emerged. This connects the crowbar resistance when necessary and disables it to resume DFIG control. The essence of this control is to limit the rotor current and to supply reactive power.

For active crowbar control schemes, the control signals are activated by the rotor-side converter devices (which are usually IGBTs). These have voltage and current limits that must not be exceeded. Therefore the rotor-side converter voltages and currents are the critical regulation reference [1][2]. The DC-link bus voltage can increase rapidly under these conditions, so it is also used for crowbar triggering [3][4]. Some researchers have assumed that the crowbar was uneconomic and have avoided the use of crowbar control. They developed a new fault control strategy [5] and converter topology [6]. However, this makes the control system very complex and increases the issues with control coordination between normal and fault operation.

In addition to the triggering and control issues, the blocking of the rotor-side converter by the switching-on crowbar is of concern. In a traditional system, the rotor-side converter is disconnected from the rotor when the crowbar is switched on. However, some studies have proposed keeping converter connected [1][7]. With this kind of control, the resumption of normal operation can be immediate after fault clearance.

Another kind of power-electronic-controlled external resistor, which is connected to the rotor windings of the generator, is used to limit the rotor acceleration during a fault. This is called a braking resistor [8]. The purpose of the braking resistor is to balance the active power then improve generator stability during a fault. The advantages of a series dynamic braking resistor, when connected to the generation circuit, were studied by [9]. It was found that this enhanced the fault ride-through of a fixed speed wind turbine. Vestas (Denmark) use pitch-regulated variable rotor resistance to realize a quasi-variable-speed wind turbine (the OptiSlip® technology [10]). In [4], a braking resistor was inserted into the DC-link between the converters of DFIG; this acts as a dump load (or DC-chopper) to smooth the DC-link voltage during heavy imbalance of active power through the rotor-side and the grid-side converter. A similar resistor was proposed in [11] to enhance the fault ride-through capability of a permanent magnet synchronous generator with fully rated converter. However, there has been no study into the use of a series dynamic resistor in a DFIG system.

In this paper, a new topology and control strategy for the protection of the converter in a DFIG system is proposed. In Section II, rotor voltage and current transients are discussed in detail. A new protection scheme for the rotor-side converter is 
proposed and simulated in Sections III-V. The method is verified by simulations using MATLAB/Simulink. The protection schemes are compared with simulations.

\section{Rotor CURRENT OF INDUCTION GENERATOR DURING DISTURBANCES}

The general Park's model of an induction generator is often used for both normal operation and transient analysis [12]. Using the motor convention in a static stator-oriented reference frame, without saturation, the voltage equations are

$$
\begin{gathered}
\vec{v}_{s}=R_{s} \vec{i}_{s}+\frac{d \vec{\psi}_{s}}{d t} \\
\vec{v}_{r}=R_{r} \vec{i}_{r}+\frac{d \vec{\psi}_{r}}{d t}-j \omega \vec{\psi}_{r}
\end{gathered}
$$

where $\vec{v}_{s}$ is grid-imposed. The rotor voltage $\vec{v}_{r}$ is invertercontrolled and performs the control. The flux equations:

$$
\begin{aligned}
& \vec{\psi}_{s}=L_{s} \vec{i}_{s}+L_{m} \vec{i}_{r} \\
& \vec{\psi}_{r}=L_{m} \vec{i}_{s}+L_{r} \vec{i}_{r} .
\end{aligned}
$$

From (3) and (4) we can eliminate $\vec{i}_{s}$ and obtain an expression to put into (2); further eliminating $\vec{\psi}_{r}$ gives

$$
\vec{v}_{r}=\frac{L_{m}}{L_{s}}\left(\frac{d}{d t}-j \omega\right) \vec{\psi}_{s}+\left[R_{r}+\left(\frac{L_{s} L_{r}-L_{m}^{2}}{L_{s}}\right)\left(\frac{d}{d t}-j \omega\right)\right] \cdot \vec{i}_{r} .
$$

With leakage factor $\sigma=\frac{L_{s} L_{r}-L_{m}^{2}}{L_{s} L_{r}}$.

And then use a voltage source to represent the voltage due to the stator flux produces

$$
\begin{gathered}
\vec{v}_{r 0}=\frac{L_{m}}{L_{s}}\left(\frac{d}{d t}-j \omega\right) \vec{\psi}_{s} . \\
\text { So (5) becomes } \quad \vec{v}_{r}=\vec{v}_{r 0}+\left[R_{r}+\sigma L_{r}\left(\frac{d}{d t}-j \omega\right)\right] \cdot \vec{i}_{r} .
\end{gathered}
$$

The rotor voltage in (8) can be expressed in a rotor reference frame where $\vec{v}_{r}^{r}=\vec{v}_{r 0}^{r}+R_{r} \cdot \vec{i}_{r}^{r}+\sigma L_{r} \frac{d \vec{i}_{r}^{r}}{d t}$

so that the rotor equivalent circuit in Fig. 1 is obtained.

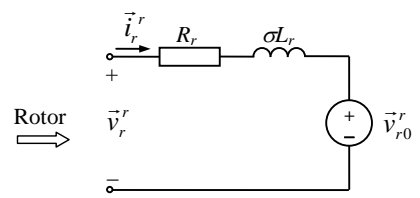

Fig. 1. Equivalent circuit of rotor circuit during faults.

We can now get the relationship between rotor voltage and current from (9). When there is a disturbance on the stator side, assume that there is a sharp voltage change from $V_{1}$ to $V_{2}$. In [12] it was shown that $\vec{v}_{r 0}^{r}$ can exceed the maximum voltage that the rotor-side converter can generate, so that current control is lost. In the same reference frame, the voltage is

$$
\vec{v}_{r 0}^{r}=V_{2} \frac{L_{m}}{L_{s}} s e^{j \omega_{s} t}-\frac{L_{m}}{L_{s}}\left(\frac{1}{\tau_{s}}+j \omega\right) \frac{V_{1}-V_{2}}{j \omega_{s}} e^{-t / \tau_{s}} .
$$

This can be simplified by omitting $1 / \tau_{s}$, which is very small:

$$
\begin{array}{cc}
\vec{v}_{r 0}^{r} & \approx V_{2} \frac{L_{m}}{L_{s}} s e^{j \omega_{s} t}-\frac{L_{m}}{L_{s}} j \omega \frac{V_{1}-V_{2}}{j \omega_{s}} e^{-t / \tau_{s}} . \\
\text { or } \quad \vec{v}_{r 0}^{r} \approx \frac{L_{m}}{L_{s}}\left[s V_{2} e^{j \omega_{r} t}-(1-s)\left(V_{1}-V_{2}\right) e^{-j \omega t} e^{-t / \tau_{s}}\right]
\end{array}
$$

Which is in the rotor reference frame. (9) is a linear differential equation for $\vec{i}_{r}^{r}$ in the time domain, which can be solved and the final expression is

$$
\begin{aligned}
\vec{i}_{r}^{r} & =\frac{1}{\sigma L_{r}}\left[e^{-\frac{R_{r}}{\sigma L_{r}} t} \int e^{\frac{R_{r}}{\sigma L_{r}} t} \vec{v}_{r}^{r}(t) d t-\frac{L_{m}}{L_{s}} s V_{2} \frac{1}{R_{r} / \sigma L_{r}+j \omega_{r}} e^{j \omega_{r} t} .\right. \\
& \left.+\frac{L_{m}}{L_{s}}(1-s)\left(V_{1}-V_{2}\right) \frac{1}{R_{r} / \sigma L_{r}-1 / \tau_{s}-j \omega} e^{-\left(1 / \tau_{s}+j \omega\right) t}\right]
\end{aligned}
$$

From the above equation we can see that the second and third bracketed terms have frequencies of $\omega_{r}$ and $\omega$ respectively. The maximum value of rotor current during fault can be as serious as five to ten times of the rated value as shown in the example in Fig. 2. The rotor current is related to the voltage $V_{1}, V_{2}$, and the slip $s$ and this will be concerned in the selection of resistance values in the Section IV.

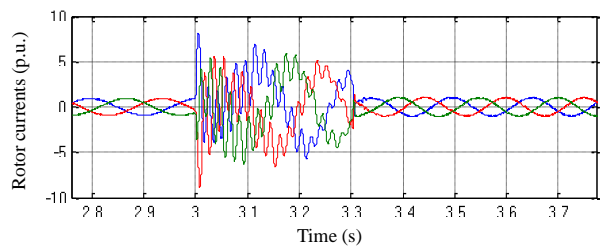

Fig. 2. Rotor currents during a disturbance without protection.

\section{CONVERTER PROTECTION SCHEMES}

\section{A. Existing Protection Methods}

Existing protection systems use crowbars, DC-choppers (for DFIGs), and series braking resistors (for permanent magnetic synchronous generators). The traditional crowbar resistor bypasses the rotor-side converter when switched on. Bi-directional thyristors [13], GTOs [2][4] and IGBTs [3] are normally used for the control of the crowbar switching. In [4] [11] a braking resistor (DC-chopper) is connected in parallel with the DC-link capacitor to limit the overcharge during low grid voltage. This protects the IGBTs from overvoltage and can dissipate energy, but this has no effect on the rotor current. In a similar way to the series braking resistor, a dynamic resistor can be put in series with the rotor (series dynamic resistor) and this limits the rotor over-current. Its operation is different from the crowbar. It can be controlled by a power-electronic switch. In normal operation, the switch is on and the resistor is bypassed; during fault conditions, the switch is off and the resistor is connected in series to the rotor winding. Fig. 3 shows the protection schemes for a DFIG converter connected to the rotor.

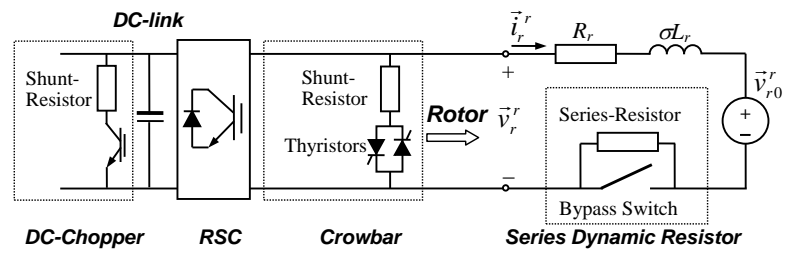

Fig. 3. Per-phase DFIG rotor equivalent circuit with protections.

\section{B. Proposed Protection Scheme}

The difference between the series dynamic resistor and the crowbar or DC-link braking resistor is its topology. The latter are shunt-connected and control the voltage while the series dynamic resistor has the distinct advantage of controlling the current magnitude directly. Therefore it not only controls the 
rotor overvoltage which could cause the rotor-side converter to lose control, but, more significantly, limit high rotor current. In addition, the limited current can reduce the charging current to the DC-link capacitor, hence avoiding DC-link overvoltage. So with the proposed series dynamic resistor, the rotor-side converter does not need to be stopped.

Two functions of a traditional crowbar are to bypass the converter and limit the current in the rotor windings. The first function is to protect for converter, while the second to protect the rotor windings. The obvious disadvantage of the bypassing function is that it turns the DFIG into a normal asynchronous machine. These need reactive power for excitation, so it will absorb reactive power from the grid that will exacerbate the voltage dip.

Using a series dynamic resistor, a new rotor-side converter protection scheme is proposed by dividing the two functions of crowbar. The shunt crowbar keeps its bypass function while the rotor current limit function is partially taken over by a series dynamic resistor. Hence, the crowbar limits the rotor winding over-current and the series dynamic resistor limits the converter over-current. Therefore the series dynamic resistor is the primary protection, and the crowbar resistor can further bypass the rotor-side converter during a deteriorating fault. While the combination of the two resistors can protect the converter system, a DC-link bus overvoltage may still occur due to the fault.

The DC-chopper across DC-link is not essential for fault ride-through operation but it smoothes the DC-link voltage and increases the normal range of the DFIG operation during heavy imbalances of active power between the converters [4]. For a recovering of fault, the grid-side converter current may have transients that can charge the capacitor so that the chopper can function. In this paper, the series dynamic resistor and crowbar are combined and used for rotor-side converter protection.

\section{Triggering-on/-off Sequence of $C B$ and SDR}

In a time sequence, the series dynamic resistor should be switched on first. If the rotor current still increases the crowbar offers further protection. However, for a serious fault, the most important feature of the rotor current during the disturbance is its abrupt change immediately after the fault as shown in Fig. 2. Because of the rotor winding impedance the current will decrease if the fault does not deteriorate so it is critical to protect the converter from the first peak. However, for the series dynamic resistor and crowbar, there are switching delays in the protection triggering. In a serious fault, the series dynamic resistor is first triggered but it cannot limit the high current, however it may be that there is insufficient time to switch-in the crowbar to protect it from the first-peak. To deal with this, a switching sequence strategy has to be used which includes the pre-crowbar protection as shown in Fig. 4.

If the current goes beyond the extreme limit, the crowbar is switched in the first instance. At almost the same time, the series dynamic resistor is triggered. After a drop in over-current the crowbar can be switched off with only the series dynamic resistor in operation. The process from (a) to (d) is utilized over the first cycle of a large rotor over-current. After this period the system is in a new steady state. If the fault deteriorates, or during the voltage recovery transient the rotor current goes high again, the crowbar can be switched on once more as further protection in conjunction with the series dynamic resistor, i.e., during a serious fault, the process is:

(a) $\rightarrow$ (b) $\rightarrow$ (c) $\rightarrow$ (d) $\rightarrow$ (c) $\rightarrow$ (d) $\rightarrow$ (a) as shown in Fig. 5 .
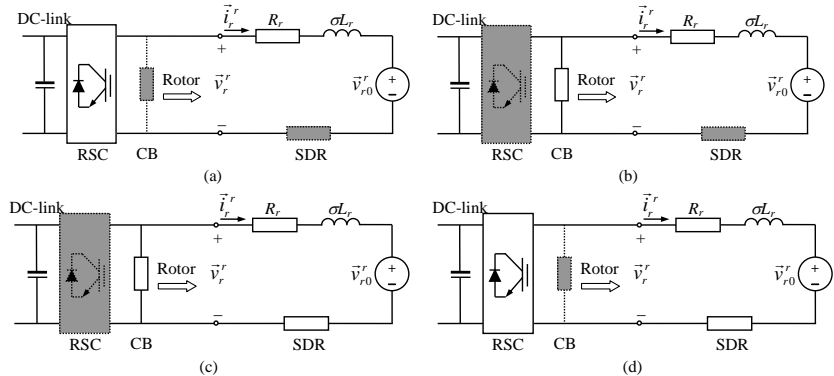

Fig. 4. Switching sequence of converter protection scheme.

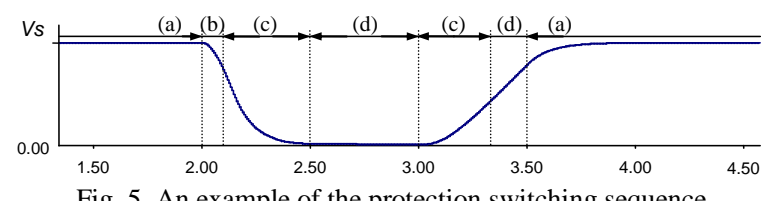

Fig. 5 An example of the protection switching sequence

It is estimated that the first peak of the three-phase rotor current happens during the first cycle of oscillating $\omega$ term in (13). Hence crowbar is switched on for $t_{-}$Pre $=T=2 \pi / \omega=$ $2 \pi /(1-s) \omega_{s}$, where $\omega_{s}$ is of the synchronous frequency.

For a gradual or moderate fault, the series dynamic resistor is switched on first and the crowbar can be turned on when necessary depending on the fault development.

\section{Protection Switching Strategy}

To coordinate with the above protection arrangement, a switching strategy, which includes converter protection, is proposed in Fig. 6. Both the rotor current $i_{r}$ and voltage $v_{r}$ are monitored and compared with preset threshold values $I_{t h}$ pre, $I_{t h}$, $V_{t h}$ pre and $V_{t h}$. If either exceeds the threshold value, the output of the comparator is 1 , else it is 0 . A single 1 triggers the protection. The timer for pre-crowbar is switched on to enable the converter. At the same time, another timer is triggered for a period whilst the series dynamic resistor on. If during this period either the current $i_{r}{ }^{\prime}$ or voltage $v_{r}{ }^{\prime}$ with a series dynamic resistor exceeds the new threshold values $I_{t h}{ }^{\prime}$ and $V_{t h}{ }^{\prime}$, the crowbar protection is switched on and the rotor-side converter IGBTs can be turned off for further protection. $I_{t h}{ }^{\prime}$ and $V_{t h}{ }^{\prime}$ are less than $I_{t h}$ and $V_{t h}$ because the IGBTs have been in a fault condition for a period so that the safe operating area has to be reduced.

With the timer and piecewise protection, the system can cope with the piecewise grid code requirements for fault ride-through. The rotor-side converter can continue to work and control the active and reactive power through the fault. The reference threshold values of $I_{t h}$ pre $, I_{t h}, I_{t h}{ }^{\prime}, V_{t h \_p r e}, V_{t h}$ and $V_{t h}{ }^{\prime}$ need to be set or obtained by a control calculation scheme.

For switch-off control, the opposite procedure is followed. And the rotor current RMS or average value is monitored to avoid unnecessary frequent switching due to the high frequency current fluctuation. If the value decreases to below the second threshold $I_{t h}{ }^{\prime}$, then crowbar is switched off. The series dynamic resistor is switched out when the rotor current falls to below the rated value. 


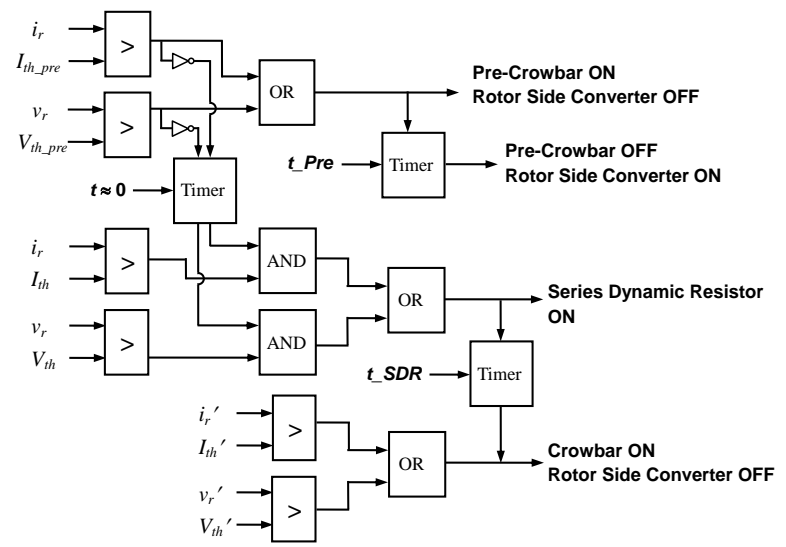

Fig. 6. Wind turbine system protection strategy with converter protection.

\section{Resistance VAlue Limits of SERIES Dynamic RESISTOR AND CROWBAR}

\section{A. Traditional Crowbar Resistance}

For single crowbar protection, the double function means the resistance has to have both a lower and an upper limit. The minimum value is related to the rotor winding over-current limit, while the maximum is set by the over-voltage on the converter terminals [13].

Here we use the approximated crowbar resistance calculation from [13]. The estimated maximal rotor current is

$$
i_{r, \max } \approx \frac{1.8 V_{s}}{\sqrt{X_{s}^{\prime}+R_{C B}^{2}}} .
$$

The voltage across the bypass resistors, and thus across the rotor and converter is $\sqrt{2} V_{r} \approx R_{C B} i_{r, \text { max }}$.

From (14) and (15) we obtain $R_{C B, \max }=\frac{\sqrt{2} V_{r, \text { max }} \omega_{s} L_{s}^{\prime}}{\sqrt{3.2 V_{s}^{2}-2 V_{r, \text { max }}^{2}}}$

where $\quad L_{s}^{\prime}=L_{s}+\frac{L_{r} L_{m}}{L_{r}+L_{m}}$

$V_{s}$ is the stator voltage RMS before a fault, $V_{r, \max }$ is the upper limit RMS value of the rotor-side converter voltage. Both are chosen of rated value. So in a per-unit calculation

$$
R_{C B, \max }=1.29 L_{s}{ }^{\prime} \text {. }
$$

\section{B. Combined Protection Resistances}

With the above transient analysis and from the switching sequence of protection scheme, the resistance values for the series dynamic resistor $R_{S D R}$ and the crowbar $R_{C B}$ can be calculated from the equivalent circuit in Fig. 4, in terms of the stator voltage magnitude changes, slip and rotor speed. In (13), substitute $R_{r}$ with $R_{T}$ (which will be $R_{r}+R_{S D R}$ or $R_{r}+R_{S D R}+R_{C B}$ depending on the fault level) and $\vec{v}_{r}^{r}$ with the constant limit voltage $V_{t h}$ or $V_{t h}{ }^{\prime}$. $R_{r}$ and $\sigma L_{r}$ are known parameters. With the condition $\vec{i}_{r}^{r} \leq I_{t h}$ or $I_{t h}^{\prime}, R_{T}$ can be expressed in terms of $V_{1}, V_{2}$, and $s$. At $t=$ 0 , omitting $1 / \tau_{s}$ in denominator of the third component

$$
\left|\vec{i}_{r, \text { max }}^{r}\right|=I_{t h}=\mid \frac{V_{t h}}{R_{T}}+\frac{L_{m}}{\sigma L_{r} L_{s}}\left[\begin{array}{l}
(1-s)\left(V_{1}-V_{2}\right) \frac{1}{R_{T} / \sigma L_{r}-j \omega} \\
-s V_{2} \frac{1}{R_{T} / \sigma L_{r}+j \omega_{r}}
\end{array}\right]
$$

The fault ride-through specifications can be used to divide the boundaries of $V_{1}, V_{2}$, and $s$ for $R_{S D R}$ and $R_{C B}$. Fig. 7 shows an example grid code for fault ride-through. When the stator voltage is below the curve, the wind turbine can be disconnected.

In the example, the wind turbine should withstand a 0.85 to $1.00 \mathrm{p} . u$. voltage dip for $0.2 \mathrm{~s}$. When there is $0.50 \mathrm{p}$.u. voltage, it is required that the wind turbine should provide reactive power and be connected for $1.5 \mathrm{~s}$. In this case, $R_{S D R}$ is firstly calculated by the criteria of 0.50 p.u. for $0.2 \mathrm{~s}$. If the disturbance fault is more serious or is sustained for a longer period, $R_{C B}$ is calculated for the further fault conditions.

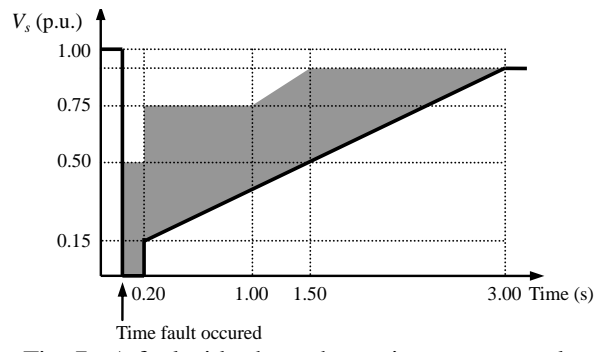

Fig. 7. A fault ride-through requirement example.

For series dynamic resistor operation: $R_{T}=R_{r}+R_{S D R}$. The most serious condition can be obtained when $s=-0.3$ p.u., $\omega=$ 1.3 p.u., $V_{1}-V_{2}=0.5$ p.u.. Hence the $R_{S D R \text {,min }}$ can be obtained. For the series dynamic resistor with crowbar operation: $R_{T}=$ $R_{r}+R_{S D R}+R_{C B}$. Again, the most serious condition can be obtained when $s=-0.3$ p.u., $\omega=1.3$ p.u., $V_{1}-V_{2}=1.0$ p.u. so that minimum crowbar resistor $R_{C B \text {,min }}$ can be obtained. The maximum value can be obtained in a similar way to the single crowbar resistor by adding $R_{C B}$ to $R_{S D R}$ in (14):

$$
R_{C B, \max }=1.67 R_{S D R}+0.33 \sqrt{40 R_{S D R}^{2}+15 L_{s}^{\prime 2}}
$$

\section{Simulation Results AND Discussion}

The proposed converter protection method is simulated in MATLAB/Simulink. The generator parameters are listed in TABLE I. $R_{S D R}$ and $R_{C B}$ are calculated as the example code requirements in the above section. The threshold values are set as $I_{t h \_p r e}=3 I_{r n}, V_{t h \_p r e}=V_{r n} ; I_{t h}=2 I_{r n}, V_{t h}=V_{r n} ; I_{t h}{ }^{\prime}=0.9 I_{t h}, V_{t h}{ }^{\prime}=0.9 V_{t h}$. The slip is chosen as normal operation condition, i.e. $s=-0.1$ p.u. The calculated values are $R_{S D R, \min }=0.059 \Omega=0.098$ p.u., $\quad R_{C B, \min }=$ $0.029 \Omega=0.048$ p.u.. From (20), $R_{C B, \max }=0.26$ p.u. $=0.156 \Omega$. In simulations, $0.06 \Omega$ and $0.03 \Omega$ are chosen as the resistances. The faults simulated are based on the fault ride-through examples: 1) a serious three-phase grounding which begins at $t=4.0 \mathrm{~s}$ and clears at $t=4.2 \mathrm{~s} \mathrm{(Fig.} \mathrm{8)} \mathrm{and} \mathrm{2)} \mathrm{a} \mathrm{0.5p.u.} \mathrm{voltage} \mathrm{dip} \mathrm{for} \mathrm{1.5s} \mathrm{(Fig.} 9$ and Fig. 10 with series dynamic resistor and crowbar protection respectively).

Series dynamic resistor and single crowbar protection systems are compared for the second fault condition. (18) is used in the single crowbar $R_{C B, \max }$ calculation with per-unit values, so $R_{C B, \max }$ $=0.105$ p.u. $=0.063 \Omega$. This is used in the crowbar simulation.

TABLE I GENERATOR PARAMETERS
\begin{tabular}{|l|l||l|l|}
\hline Parameter & Value & Parameter & Value \\
\hline Rated power $P_{n}$ & $2 \mathrm{MW}$ & Ratio $N_{s} / N_{r}$ & 0.63 \\
\hline Rated stator voltage $V_{s n}$ & $690 \mathrm{~V}$ & Inertia constant $H$ & $3.5 \mathrm{~s}$ \\
\hline Rated frequency $f_{s}$ & $50 \mathrm{~Hz}$ & Pole pair no. $P_{p}$ & 2 \\
\hline Stator leakage inductance $L_{l s}$ & $\begin{array}{l}0.105 \\
\text { p.u. }\end{array}$ & Stator resistance $R_{s}$ & 0.005 p.u. \\
\hline Rotor leakage inductance $L_{l r}$ & 0.11 p.u. & Rotor resistance $R_{r}$ & 0.0055 p.u. \\
\hline Magnetizing inductance $L_{m}$ & $\begin{array}{l}3.953 \\
\text { p.u. }\end{array}$ & & \\
\hline
\end{tabular}




\section{A. Protection Performance Results}

The combined converter protection results are shown in Fig. 8. As in Fig. 1, the total voltage dip results in about eight times the rated value of current. So the crowbar is switched on first for the first cycle of the high frequency component, i.e. $t_{-}$Pre $=T=2 \pi t \omega=$ $2 \pi 1.1 \omega_{s}=0.0182 \mathrm{~s}$. The series dynamic resistor is also switched on when fault occurs and remains connected until recovery. The big transients in the recovery period make the crowbar switched on again for about $t_{-}$Pre. With the combined protection, the rotor current is effectively restricted to within 2.0 p.u. with the rotor-side converter disabled for only $0.0364 \mathrm{~s}$. Hence the time of the rotor-side converter operation is effectively prolonged.

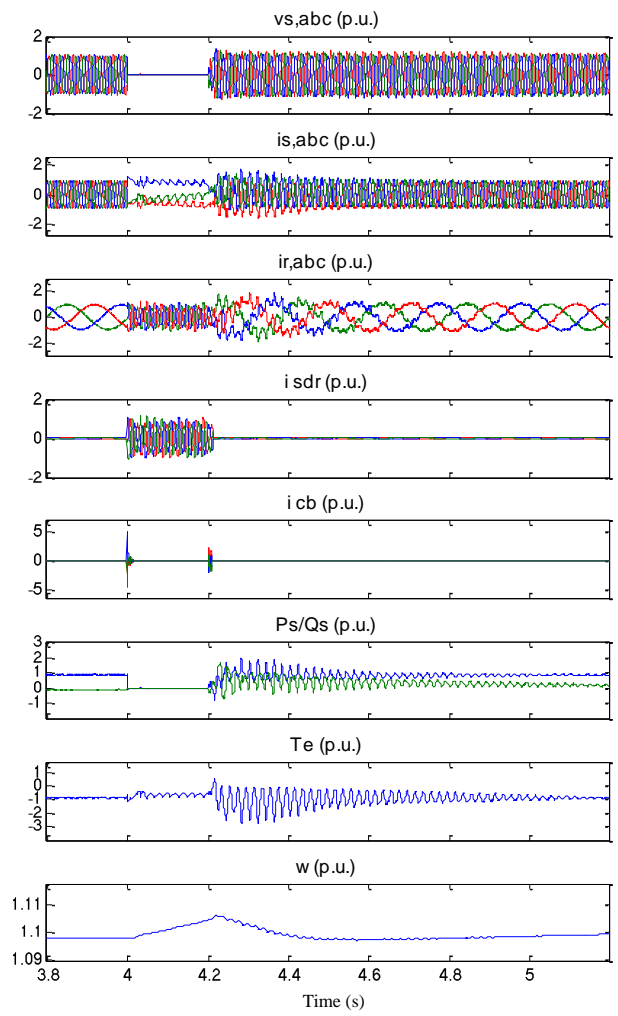

Fig. 8. With combined converter protection, voltage dip of 1 p.u. for $0.2 \mathrm{~s}$.

\section{B. Fault Ride-Through Performance Comparison}

The rotor current, reactive power, electrical torque and rotor speed of a DFIG, when series dynamic resistor and crowbar protection systems are used, are simulated and compared in Figs. 9 to 11. These show the DFIG performance under these protection schemes. To clarify, only single protection strategies are simulated instead of combined protection and this allows the observation and comparison of the different protection strategies when used individually.

Both of the two strategies experience big reactive power and electrical torque fluctuations during the fault clearance. This is related to sudden stator current changes. The second reactive power graph in Fig. 11 is zoomed to show the reactive power supply. It can be seen that with the rotor-side converter connected in series dynamic resistor protection, about 0.1 p.u. reactive power is provided. However, for crowbar protection, the asynchronous machine absorbs reactive power of about 0.1 p.u.. So in terms of grid voltage recovery, series dynamic resistor protection has its advantages.

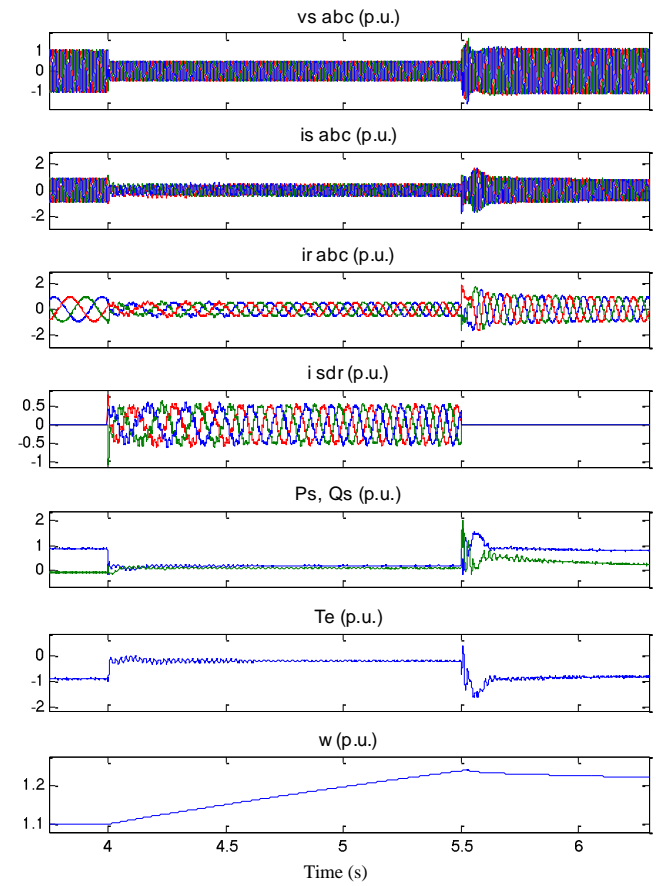

Fig. 9. With series dynamic resistor protection, voltage dip of 0.5 p.u. for $1.5 \mathrm{~s}$.
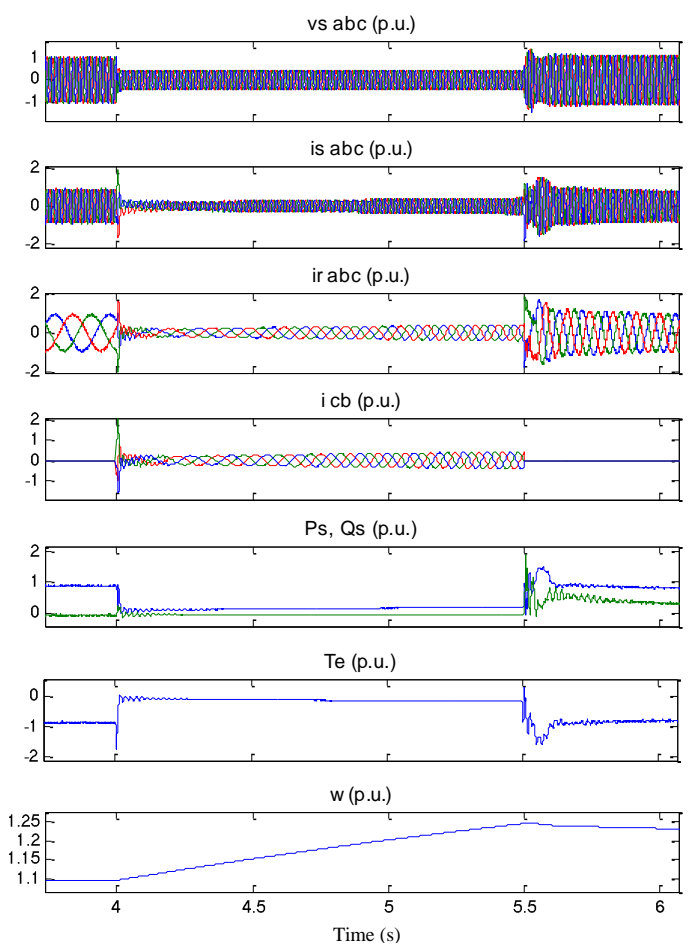

Fig. 10. With crowbar protection, voltage dip of 0.5 p.u. for $1.5 \mathrm{~s}$.

The reactive power and electrical torque ripples are larger with series dynamic resistor protection compared to crowbar protection. This is probably due to the big resistance in rotor winding and DFIG control system performance during faults, which needs further detailed work. For rotor speed changes they are virtually the same. This means the series dynamic resistor avoids rotor over-speed as effectively as crowbar.

\section{Discussion}

The switching times of the crowbar and series dynamic resistor power-electronic switches are not considered in the 
analyses and simulations. In reality, this may be an issue, especially for the pre-crowbar phase when fast response is required. In many practical applications, the crowbar thyristor switches cannot interrupt the current before zero-crossing [14]. This can also influence the protection performance.
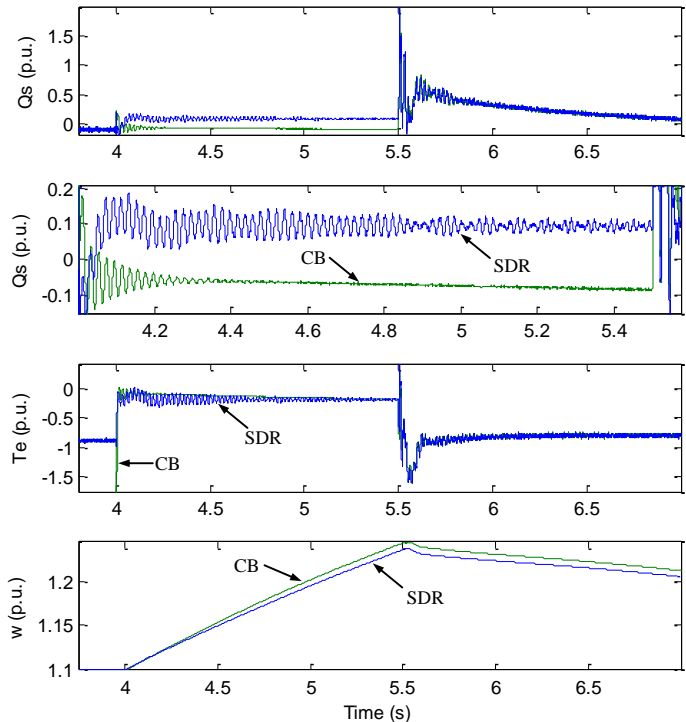

Fig. 11. Protection comparison, voltage dip of 0.5 p.u. for $1.5 \mathrm{~s}$.

In the simulations, a simple star-connected resistor connection is used for the crowbar. The operation resistance of the rotor-side converter is set to $0.0001 \Omega$. This is even smaller than the calculated $R_{C B}$, min so this leads to malfunction of the bypassing. To maintain rotor-side converter connection (this is better for immediate control recovery), a switch is used to transfer between the rotor-side converter and the crowbar to enable its function. Hence crowbar and series dynamic resistor switching needs to be studied to ensure fast and effective protection of the converter.

The calculated theoretical values of $R_{S D R}$ and $R_{C B}$ need to be checked for both the temperature rise and physical dimensions for practical use. An IGBT-based switch should be picked by rated voltage, current and also thermal temperature rise limitation. Power electronic switches for partially-rated converter are usually compact and suitable for placement in the wind turbine nacelle.

The grid-side converter can contribute as a reactive compensator with limited reactive power generation capacity (about 0.3 p.u. of the converter rating). This is related to the grid-side converter current and DC-link capacitor charging.

The series dynamic resistor is realized by power electronic switch. However, the bypass switch that is closed during normal operation will produce additional losses, specifically device on-state losses. But this is negligible in comparison with the MW rating of the wind turbine. The reliability of the wind turbine might be reduced due to the possible malfunction of the power electronic switches.

\section{CONCLUSION}

Converter protection is necessary for DFIG wind turbine systems during faults. The method proposed in this paper is for over-current and -voltage protection of devices in the rotor-side converter. Various resistor protection schemes were reviewed.
Fault ride-through code requirements were used to find the best triggering times for the series dynamic resistor and crowbar to maximize the operation time of the rotor-side converter. The resistance calculations for the series dynamic resistor and crowbar were described for further application reference. These values were calculated using an expression for rotor current and code requirements.

The series dynamic resistor can be in operation with the rotor-side converter control without bypassing it. For the control of the grid-side converter to DC-link bus voltage, the resumption time can be shorter than for a system with normal active crowbar protection, which is helpful for resuming normal control which provides reactive power for grid voltage support. During this process, inspection of the reactive power, electrical torque, and rotor speed fluctuations show that the proposed method enhances DFIG fault ride-through capability.

\section{REFERENCES}

[1] J. Morren, and S.W.H. de Haan, "Ridethrough of wind turbines with doubly-fed induction generator during a voltage dip," IEEE Trans. Energy Convers., vol. 20, no. 2, pp. 435-441, Jun. 2005.

[2] P. Zhou and Y. He, "Control strategy of an active crowbar for DFIG based wind turbine under grid voltage dips," in Proc. Int. Conf. Electrical Machines and System. 2007, Seoul, Korea, Oct. 8-11, 2007.

[3] M. Rodríguez, G. Abad, I. Sarasola, and A. Gilabert, "Crowbar control algorithms for doubly fed induction generator during voltage dips," in Proc. 11th Eur. Conf. Power Electronics and Applications, Dresden, Germany, Sep. 11-14, 2005.

[4] I. Erlich, J. Kretschmann, J. Fortmann, S. Mueller-Engelhardt, and H. Wrede, "Modeling of wind turbines based on doubly-fed induction generators for power system stability studies," IEEE Trans. Power Syst., vol. 22, no. 3, pp. 909-919, Aug. 2007.

[5] D. Xiang, R. Li, P. J. Tavner, and S. Yang, "Control of a doubly fed induction generator in a wind turbine during grid fault ride-through," IEEE Trans. Energy Convers., vol. 21, no. 3, pp. 652-662, Sep. 2006.

[6] A. Gaillard, S. Karimi, P. Poure, S. Saadate, and E. Gholipour, "A fault tolerant converter topology for wind energy conversion system with doubly fed induction generator," in Proc. 12th Eur. Conf. Power Electronics and Applications, Sep. 2-5, 2007.

[7] A. Dittrich and A. Stoev, "Comparison of fault ride-through strategies for wind turbines with dfim generators," in Proc. 11th Eur. Conf. Power Electronics and Applications, Dresden, Germany, Sep. 11-14, 2005.

[8] W. Freitas, A. Morelato, and W. Xu, "Improvement of induction generator stability using braking resistors," IEEE Trans. Power Syst., vol. 19, no. 2, pp. 1247-1249, May 2004.

[9] A. Causebrook, D. J. Atkinson, and A. G. Jack, "Fault ride-through of large wind farms using series dynamic braking resistors (March 2007)," IEEE Trans. Power Syst., vol. 22, no. 3, pp. 966-975, Aug. 2007.

[10] J. M. Carrasco, E. Galván, R. Portillo, L.G. Franquelo, and J.T. Bialasiewicz, "Power electronic systems for the grid integration of wind turbines," in Proc. 32nd Annual Conf. IEEE Industrial Electronics IECON 2006, pp. 4182-4188, Nov. 2006.

[11] J. F. Conroy and R. Watson, "Low-voltage ride-through of a full converter wind turbine with permanent magnet generator," IET Renew. Power Gener., vol. 1, no. 3, pp. 182-189, 2007.

[12] J. López, P. Sanchis, X. Roboam, and L. Marroyo, "Dyanmic behavior of the doubly fed induction generator during three-phase voltage dips," IEEE Trans. Energy Convers., vol. 22, no. 3, pp. 709-717, Sep. 2007.

[13] J. Morren and S. W. H. de Haan, "Short-circuit current of wind turbines with doubly fed induction generator," IEEE Trans. Energy Conversion., vol. 22, no. 1, pp. 174-180, Mar. 2007.

[14] I. Erlich, H. Wrede, and C. Feltes, "Dynamic behavior of DFIG-based wind turbines during grid faults," in Proc. Power Conversion Conf., Nagoya, Japan, Apr. 2-5, 2007. 